\title{
LA FINANCIACIÓN DE LOS PARTIDOS POLÍTICOS EN LOS ESTADOS UNIDOS*
}

\author{
SANTIAGO SÁNCHEZ GONZÁLEZ \\ Profesor Titular de Derecho Constitucional \\ Facultad de Derecho (UNED)
}

\section{INTRODUCCIÓN}

A diferencia de las Constituciones contemporáneas, la norteamericana ni siquiera menciona a los partidos políticos; lo cual es perfectamente explicable dada la fecha de su promulgación ${ }^{1}$. Las enmiendas aprobadas en 1791 tampoco incluían el derecho de asociación, el cual, al igual que otros derechos -como el derecho a votar o de libre circulación- han ido siendo reconocidos por el Tribunal Supremo mediante interpretaciones libérrimas de los distintos preceptos y de sus "penumbras"². Todo ello, desde luego, ya bien entrado el siglo xx. Así en 1958, afirmaba: "Está fuera de discusión que la libertad de asociarse para manifestar

* El único artículo publicado en España en castellano, específicamente dedicado a este tema, de que tengo conocimiento, apareció hace ya veinticuatro años en la obra Teoría y Práctica de los Partidos Políticos, Ed. de Pedro de Vega, Cuadernos para el Diálogo, Madrid, 1977; su autor fue J. R. Montero Gibert y llevaba por título "La financiación de los partidos políticos y de las elecciones en los Estados Unidos".

1. En el más propio estilo de la época, James Madison consideraba a los partidos ufacciones en contradicción con los derechos de otros ciudadanos o con los intereses permanentes y globales de la comunidad"; y Georges Washington, en su "Farewell Address" en 1796, advirtió a la nación sobre los "efectos perniciosos del espíritu de partido".

2. La palabra "penumbra" debe entenderse aquí en el sentido de frontera, borde, límite o periferia imprecisos de un derecho o libertad fundamental. El juez del Tribunal Supremo William O. Douglas recurrió a este vocablo para sostener, en el pleito Griswold v. Conneticut 381 U.S. 479 (1965), que el derecho a la vida privada - "privacy”- está comprendido bajo las penumbras, o proyectado en las emanaciones, de las Enmiendas Primera, Tercera, Cuarta, Quinta y Novena. 
creencias o propugnar ideas es un aspecto inseparable de la "libertad" garantizada por el Debido Proceso Legal de la Decimocuarta Enmienda, que incluye la libertad de expresión"?. Por lo que respecta a los partidos políticos, el Tribunal subrayaba en 1973 que "no puede existir ya duda alguna de que la libertad de asociarse con otros para la promoción común de ideas y creencias políticas es una forma de "actividad grupal ordenada" protegida por la Primera y la Decimocuarta Enmiendas [...]”. Y añadía: "El derecho de asociarse con el partido político que uno elija es una parte integrante de esta libertad constitucional básica " ${ }^{4}$.

De hecho, los partidos políticos nacieron poco después de formarse la República. Primero fueron los republicanos de Jefferson; luego, Hamilton organizó el partido de los federalistas. Y la implantación definitiva del bipartidismo tal y como lo conocemos ahora data de la segunda mitad del siglo XIX. No es pues extraño que los partidos fueran objeto de regulación estatal -California y Nueva York aprobaron en 1866 algunas normas sobre los procedimientos de selección de candidatos y sobre la designación de los cargos en el seno de los partidos-, y federal -la "Civil Service Reform Act" (1883) y la "Tillman Act" (1907), la "Publicity Act" (1909) y la "Corrupt Practices Act" de 1911-, para combatir el nepotismo y el abuso y la corrupción electorales 5 .

Desde sus orígenes las contiendas electorales en Norteamérica han sido financiadas con dinero privado procedente de individuos, asociaciones empresariales y laborales, sociedades mercantiles y partidos políticos que pretendían, en general, obtener contraprestaciones de diversa índole. La financiación publica, desde que comenzó ${ }^{6}$, se ha destinado a las elecciones presidenciales y siempre ha sido menor y sujeta a determinados condicionantes. Lo cual no significa que no se fuera consciente de los efectos perversos que una financiación exclusivamente privada entraña. Como se ha reconocido, "con anterioridad a la aprobación en 1974 de varias modificaciones de la Ley reguladora de las campañas para las elecciones federales ${ }^{7}$ (en adelante FECA), la corrupción era probablemente más la norma que la excepción en la financiación de las elecciones americanas" ${ }^{8}$.

Teniendo en cuenta que los partidos políticos en los Estados Unidos de Norteamérica son casi exclusivamente maquinarias electorales, puede afirmarse sin temor que la bistoria de la financiación de los partidos politicos en los Estados Unidos de Norteamérica es la bistoria de la financiación de las campañas electorales?.

3. N.A.A.C.P. v. Alabama, 357 U.S. 449, 460-461.

4. Kusper v. Pontikes, 414 U.S. 51, 56-57.

5. Vid. Lelio BASSO, "Il partito nell'ordinamento democratico moderno", Indagine sul Partito Politico Milano, Giuffrè Editore, 1966, p. 57.

6. La financiación pública de las elecciones presidenciales no se inició hasta 1976.

7. En el original "Federal Election Campaign Act".

8. Paul S. Herrnson, "The high finance of American Politics: Campaign spending and reform in federal elections", Campaign and Party finance in North America and Western Europe, Boulder, Westview Press Inc., 1993, p. 18.

9. “Cuando se lee sobre financiación política comparada, es importante tener presente que esta expresión adopta diferentes significados en Norteamérica, especialmente en los Estados Unidos, y en Europa. En Norteamérica realmente quiere decir financiación de candidatos y de campañas. En Europa, lo más probable es que signifique financiación de partidos. Lo cual es un reflejo tanto de que los 
Y esto es así en los tres ámbitos. En el plano federal, en el que se elige al Presidente y a los Congresistas -representantes y senadores-; en el de cada uno de los Estados miembros, donde son elegidos los gobernadores, las asambleas legislativas y diferentes cargos públicos estatales; y en el local, en el que se elige, entre otros, a los alcaldes y a los ayuntamientos - "City councils"- Cada ámbito geopolítico cuenta con normas propias, reguladoras de sus respectivos procesos electorales y de la financiación de las campañas. Sin embargo, de acuerdo con los principios de jerarquía y de competencia los gobiernos locales están sometidos a las normativas estatales y en el caso de conflicto entre las legislaciones electorales estatal y federal en materia de cargos federales, prevalece esta última. Aquí nos vamos a ocupar sobre todo de la financiación de los partidos y campañas electorales en el contexto federal.

\section{LAS NORMAS REGULADORAS}

El primer intento regulador de alcance promulgado en el siglo veinte fue la "Corrupt Practices Act" de 1925, a la que siguieron entre 1935 y 1947 otras leyes ${ }^{10}$. Todas ellas, sin embargo, resultaron inútiles en su pretensión de sanear la actividad política electoral. Claro es que no existía órgano o entidad encargada de hacerlas cumplir. Las exigencias de reforma y la insistencia en la misma se intensificaron al incrementarse los costes de las campañas como consecuencia, en particular, de los cambios en las técnicas de propaganda electoral y del papel de los medios de información de masas. El subsidio parcial con fondos federales de las elecciones presidenciales y la creación de una comisión de ambos partidos que supervisara todas las elecciones fueron algunas de las medidas propuestas.

Por fin en 1971 el Congreso aprobó la FECA. Se trataba de limitar los gastos de propaganda electoral en los medios de información y las cantidades que podían aportar a sus propias campañas los candidatos a la Presidencia y a la Vicepresidencia y sus familias. Asimismo, se preveían procedimientos para que todas las contribuciones superiores a cien dólares se hicieran públicas. De manera complementaria, se aprobó la "Revenue Act", en la que se establecían varias medidas para estimular las contribuciones y se creaba el Fondo Nacional para la Financiación de las Campañas Presidenciales. Dicho fondo, que se pondría en marcha en 1976, se nutriría exclusivamente de aportaciones voluntarias, constituidas por la suma de uno o dos dólares, que se descontarían de la cuota pagadera del impuesto sobre la renta exigible a los contribuyentes.

La oposición del partido republicano a cualquier medida reguladora determinó que se aplazara la entrada en vigor de la FECA. De otro lado, las irregu-

partidos políticos europeos son más fuertes, como de que la política en América está más orientada hacia los candidatos". Arthur B. Gunlicks, Prefacio a la obra citada en nota 8, p. vii.

10. La "Public Utilities Holding Company Act", de 1935, la "Clean Politics Act", de 1939, la "SmithConnally Act", de 1943 y la "Labor Management Relations Act", de 1947. 
laridades de la campaña presidencial de Richard Nixon durante 1972, entre las que destaca el affaire Watergate, llevaron al Congreso a modificar la FECA en 1974 -que adquiriría plena vigencia el 1 de enero de 1975-. De entre los cambios, el más importante fue la creación una nueva agencia federal, la "Federal Election Commission" (FEC), a la que se encomendaba la función de interpretar y hacer cumplir la FECA, divulgar los informes sobre la financiación de las campañas y ejecutar el programa de financiación de las presidenciales ${ }^{11}$ con fondos públicos.

La nueva norma encontró múltiples críticas y pronto -en realidad, el 2 de enero de 1975-, varios individuos y grupos demócratas y republicanos, liderados por el senador republicano por Nueva York, James L.Buckley, cuestionaron su constitucionalidad en un litigio que fue decidido por el Tribunal Supremo un año después-el 30 de enero de 1976- de la aprobación de aquélla. En la decisión per curiam $^{12}$ más larga jamás escrita (Buckley v. Valeo 434 U.S. 1, 1976), que luego examinaremos, el Tribunal admitió la constitucionalidad de la financiación publica de las elecciones presidenciales y la competencia del Congreso para condicionar la aceptación de los fondos públicos. También estimó constitucional el establecimiento de la obligación de los candidatos y de los comités de informar sobre las contribuciones que recibieran y la difusión de las mismas. En fin, encontró plenamente justificada la fijación de topes en las contribuciones a las campañas para impedir la corrupción electoral y la apariencia de la misma. Pero juzgó inconstitucionales las limitaciones de los gastos en que pudiera incurrir un candidato que no hubiera recibido financiación pública, las restricciones de los gastos independientes realizados en apoyo, o en contra, de determinado candidato, y los topes en los gastos de un candidato financiados con dinero propio o de su familia. El Tribunal, por otro lado, dispuso que el procedimiento previsto para nombrar a los miembros de la "Federal Election Commission" -por el Speaker de la Cámara y por el Presidente del Senado- suponía una violación del principio de la separación de poderes.

Para dar cumplimiento a la sentencia, el Congreso estadounidense reformó la norma en mayo de 1976, suprimiendo las restricciones de los gastos y diseñando una nueva composición de la Comisión ${ }^{13}$. En 1979, otra ley introdujo ulteriores modificaciones destinadas a simplificar los deberes de divulgación sobre los fondos recaudados y desembolsados y a dotar de un amplio margen de libertad a los partidos locales y estatales en materia de gastos electorales en las elecciones presidenciales ${ }^{14}$.

11. No se preveía sistema público alguno de subvención de las elecciones a la Cámara de Representantes y al Senado. cado.

12. Una opinión "per curiam" es aquélla en la que el autor de la misma no aparece identifi-

13. A partir de entonces, de los ocho miembros de la FEC seis, tres demócratas y tres republicanos, los designa el Presidente y los ratifica el Senado; y los dos restantes son los Secretarios Generales de las dos Cámaras, con voz pero sin voto.

14. Para obtener una información detallada sobre la FEC y la normativa federal de financiación de las campañas electorales puede consultarse en Internet la dirección siguiente: http://www.fec.gov. 


\section{LAS SENTENCIAS DEL TRIBUNAL SUPREMO ${ }^{15}$}

"La normativa sobre financiación de las campañas electorales es tanto el resultado de la decisiones de los tribunales como de los trabajos del poder legislativo" ${ }^{16}$. Esta frase, pronunciada por Laurence M. Noble, General Counsel, del Comité del Senado sobre Asuntos Gubernamentales el 25 de septiembre de 1997, ilustra con claridad el estado del objeto de nuestro análisis.

Pues bien, en el marco de las decisiones de los tribunales hay que comenzar necesariamente con el análisis de la Sentencia recaída en el caso Buckley v. Valeo, de 1976. La razón de la supuesta inconstitucionalidad alegada por el senador Buckley y los demás demandantes fue que la FECA de 1974 entrañaba una limitación injustificada e inadmisible a la luz de la libertad de expresión amparada en la Primera Enmienda. La sentencia aceptó el planteamiento de la litis en esos términos y anuló las restricciones legales de los gastos de campaña, incluidos los gastos independientes por: 1) no considerarlas necesarias para impedir la corrupción; 2) porque esas limitaciones implicaban una seria amenaza a las libertades de expresión y de asociación; y 3) porque el deseo de los legisladores de asegurar a todos los candidatos debidamente cualificados un acceso al público en condiciones de igualdad no era causa suficiente para justificar cualquier forma de regulación que restringiera la libertad expresión. Para alcanzar esas conclusiones el Tribunal Supremo partió de una premisa más que discutible: equiparar los desembolsos destinados a financiar campañas electorales con un típico ejercicio de la libertad de expresión; y, una vez sentado ese presupuesto, se limitó a aplicar el criterio de revisión judicial más exigente $^{17}$, utilizado en múltiples ocasiones previas para enjuiciar otras limitaciones de la libertad de expresión; es decir, considerar la regulación de los gastos electorales como inconstitucional salvo en el supuesto de que dicha regulación fuera absolutamente indispensable para proteger un interés gubernamental imperioso -compelling" en el original-. En palabras del Tribunal: "Las limitaciones de contribuciones y gastos inciden en un ámbito de las actividades más fundamentales previstas en la Primera Enmienda. La discusión de los problemas públicos y el debate sobre los méritos de los candidatos forman parte del funcionamiento del sistema de gobierno

15. Las dos principales, a mi juicio, son Buckley v.Valeo 424 U.S. 1 (1976) y First National Bank of Boston v. Bellotti 435 U.S. 765 (1978). Pero también hay que mencionar las siguientes: California Medical Association v. Federal Election Commission 453 U.S. 182 (1981); Citizens Against Rent Control v. City of Berkeley 454 U.S. 290 (1981); Brown v. Hartlage 456 U.S. 45 (1982); Federal Election Commission v. National Conservative Political Action Committee 470 U.S. 480 (1985); Federal Election Commission v. Massachusetts Citizens for Life Inc.479 U.S. 238 (1986); Austin v. Michigan Chamber of Commerce 494 U.S. 652 (1990); Keller v. State Bar of California 496 U.S. 1 (1990); McIntyre v. Obio Elections Commission 514 U.S. 334 (1995); y Colorado Republican Committee v. Federal Election Commission 518 U.S. 604 (1996). El procedimiento seguido para citar es el común: primero, el nombre del litigio (demandante contra demandado), luego el número del volumen de la colección donde se recogen todos los casos, que es, en este supuesto, el de "United States Reports"; y finalmente el número de la página donde se inicia la transcripción de la sentencia y el año en que se dictó.

16. Citada por Lisa Klein en su aportación "Political Party Funding and Campaign Finance in the USA", en The Funding of Political Parties: Europe and Beyond, Ed. By K.D.Ewing, CLUEB, Bologna, 1999.

17. El "strict scrutiny test". 
establecido por nuestra Constitución [...]. Los intereses del gobierno expuestos en apoyo de la Ley implican una supresión de la comunicación. Los intereses a los que la Ley sirve incluyen la restricción de las voces de gente y de grupos que disponen de dinero para gastar [...]. La Ley se dirige en parte a igualar la relativa capacidad de influencia en los resultados electorales de todos los votantes, estableciendo un techo a los gastos en expresión política de ciudadanos y grupos. [...] Cualquier restricción en la cantidad de dinero que una persona o grupo puedan gastar en comunicación política durante una campaña reduce necesariamente la cantidad de expresión, puesto que limita el número de problemas debatidos, la profundidad de su análisis y la dimensión de la audiencia a la que alcanza. Y esto sucede porque prácticamente cada medio de comunicar ideas en la sociedad de masas de hoy requiere gastar dinero. La distribución de la más humilde hoja volante o panfleto supone una serie de costes de impresión, papel y circulación. Los discursos y las reuniones precisan por lo general alquilar un local y hacer publicidad del evento. El hecho de que el electorado dependa cada vez más de la televisión, la radio, y otros medios de comunicación de masas para obtener noticias e información ha convertido a estos modos de comunicación caros en instrumentos indispensables de cualquier discurso o mensaje político efectivo". [...] "En suma, aunque las limitaciones de las contribuciones y de los gastos previstas en la Ley implican ambas intereses fundamentales de la Primera Enmienda, los topes en los gastos imponen restricciones más severas sobre las libertades protegidas de expresión política y de asociación que las limitaciones de las contribuciones financieras".

Las críticas de la decisión en el litigio Buckely $v$. Valeo fueron numerosísimas, duras y sobre aspectos muy distintos. Así, se dijo que el Tribunal Supremo había impuesto su opinión sobre la del Congreso en un ámbito en el que por tratarse de opciones políticas, la decisión competía claramente a éste último ${ }^{18}$. Se afirmó, también, que las premisas de las que partió el Tribunal no eran compatibles con el principio democrático porque suponían: 1) que la libertad de expresión era una libertad de los individuos considerados separadamente y 2) que dicha libertad consistía en la ausencia de restricciones gubernamentales -excepto en el marco de la radiodifusión y televisión-19. Burt Neuborne retomó en parte estos argumentos cuando expuso la incoherencia de una Primera Enmienda centrada en la idea de autonomía individual en un contexto democrático, en un artículo que significativamente comenzaba con la siguiente frase: "Uno de los pronunciamientos cardinales de Buckely $v$. Valeo fue el rechazo total del poder de la mayoría política para imponer límites en nombre de la igualdad política en los gastos realizados por los ricos en las campañas electorales ${ }^{20}$. En fin, Cass Sunstein apuntó que

18. Dean ALFange, Jr., "Freedom of speech, judicial review, and public policymaking in the United States", Constitutional Democracy. Essays in Comparative Politics, Boulder, Co., Westview Press, 1983, pp. 63-82.

19. John L. Hodge, "Democracy and Free Speech", The First Amendment Reconsidered, New York, Longman, 1982.

20. Burt Neuborne, "Toward a democracy-centered reading of the First Amendment", Northwestern University Law Review, 93, 1999, pp. 1055-1074. 
Bucley era el heredero directo de Lochner ${ }^{21}$, porque uno y otro eran fruto del entendimiento de que, a efectos constitucionales, la distribución de la riqueza existente debe aceptarse como una realidad que esta ahí y que los esfuerzos para cambiar tal distribución no están permitidos ${ }^{22}$. A decir verdad, las terminantes palabras del Tribunal Supremo no permitieron para albergar dudas al respecto: "La idea de que el gobierno puede restringir la expresión de algunos elementos de nuestra sociedad a fin de aumentar la voz relativa de otros es totalmente ajena a la Primera Enmienda ${ }^{23}$.

En la misma línea, defensora de los intereses económicos de los más poderosos, se sitúa la sentencia recaída en el litigio First National Bank v. Bellotti, iniciado por el Banco mencionado por considerar inconstitucional una ley del Estado de Massachusetts que prohibía a las empresas mercantiles - "corporations" ${ }^{24}$ - realizar gastos en las campañas para influir en el voto en supuestos de democracia directa, como referendos e iniciativas legislativas, que no afectaran a sus propiedades, negocios o activos. Según el Tribunal Supremo, el Tribunal Superior de Justicia del Estado, que había confirmado la constitucionalidad de la norma, abordó el problema erróneamente, ya que la cuestión no era si las empresas mercantiles eran titulares de los derechos amparados por la Primera Enmienda, sino si la ley del Estado de Massachussetts restringía la libertad de expresión, o, en otros términos, el problema no era el derecho de las empresas a expresarse, sino (i) el derecho del pueblo a obtener información, a ser informado $(\mathfrak{i})^{25}$. Lewis Powell, autor de la opinión del Tribunal, sostuvo que una empresa mercantil es una persona a los efectos constitucionales y que, por lo tanto, debe ser tratada igual que cualquier otra (persona natural) cuando se plantean problemas relativos a la Primera Enmienda. Y añadió: "El valor inherente de la libre expresión en términos de su capacidad para informar al público no depende de la identidad de su fuente, de si se trata de una sociedad anónima, de una asociación, de una unión o de un individuo" ${ }^{26}$.

21. En el caso Lochner v. New York 198 U.S. 45 (1905), el Tribunal Supremo estableció que una ley que limitaba el número de las horas de trabajo en una panadería suponía una violación del debido proceso legal, previsto en la Enmienda Decimocuarta.

22. Cass R. SunSTEIn, "Lochner's legacy", Law and Liberalism in the 1980's, New York, Columbia University Press, 1991, pp.164-165. Idea esta reiterada en Democracy and the Problem of Free Speech, New York, The Free Press, 1993, esp. pp.97-98.

23. Buckley v. Valeo, 424 U.S. 48-49.

24. No utilizo la palabra castellana "Corporaciones" porque no su significado no es el mismo. Una corporación es uun cuerpo o comunidad, generalmente de interés público, y a veces reconocida por la autoridad", según el Diccionario de la R.A.E.; mientras que una "corporation" -en inglés norteamericano- es "una asociación de accionistas (o incluso un único accionista), creada por la ley y considerada como una persona artificial por los tribunales" (Steven H. GifIs, Law Dictionnary, Barron's, New York, 1994, p.101.

25. Las interjecciones son mías. Y la razón para introducirlas es obvia: aquí paradójicamente no aparece la concepción tradicional norteamericana de la libertad de expresión "centrada alrededor del individuo", como un derècho exclusivo de la persona que se expresa, del "speaker". Mas bien se piensa en el sujeto pasivo, en la audiencia, en el lector, del mensaje o de la información.

26. 435 U.S. 765, 777. El origen de la consideración judicial de las "Corporations" como personas a efectos constitucionales se remonta al caso Santa Clara County $v$ Southern Pacific Railway 118 U.S. 394 (1886), 395-396. 
"Si la Primera Enmienda es más que un coto privado de los medios de información -que seguramente lo es-, entonces el significado pleno de Bellotti es evidente. Aquellos con dinero, con tal de que sean "corporations", disponen ya de una "carte blanche" para tratar de manipular el proceso político. El vientre recóndito de la vida política norteamericana es ahora doctrina constitucional. Eso hace a las "Corporations" más iguales, como habría dicho Orwell, que a las personas naturales, las cuales por ley federal están limitadas en sus contribuciones electorales. Aunque las limitaciones de las contribuciones a campañas son válidas -según Buckley v. Valeo, 424 U.S. 1, 29-, los gastos de campaña personales están sólo limitados por la riqueza de la persona. Ciertamente, también existen límites aplicables a las "corporations" en cuanto a lo que pueden contribuir para un candidato. Después de Bellotti, sin embargo, son libres de hacer suyas las mismas ideas de un candidato determinado, y quizás al propio candidato, porque carecen de conexión directa con ese candidato. La conclusión es clara: el dinero habla en el proceso político. Lo cual es, obviamente, una verdad de perogrullo conocida por todos, pero que ha sido elevada a norma constitucional ${ }^{27}$.

Para concluir esta breve exposición de algunas de las sentencias del Tribunal Supremo dignas de mencionarse en materia de financiación de partidos, hay que recordar dos que merecen consideración aparte, porque permiten entrever una orientación distinta de la de evitar meramente las conductas ilícitas o la apariencia de las mismas en el proceso electoral, es decir, la corrupción. Son las dictadas en los casos Federal Electoral Commission v. Massachusetts Citizens for Life, Inc. ${ }^{28}$ Y Austin v. Michigan Chamber of Commerce ${ }^{29}$.

En la primera de ellas, el Tribunal anuló las limitaciones a los gastos en que podía incurrir una asociación para influir en la elección de determinados candidatos, porque el objeto social no era la obtención de beneficios crematísticos, sino "el estimulo del respeto por la vida humana y la defensa del derecho a la vida a través de actividades educacionales, políticas y e otro tipo". Pero "obiter dicta" se decía que "el gasto directo que una "corporation" destina a actividades políticas abre la probabilidad de que recursos amasados en el mercado económico puedan ser utilizados para proporcionar una ventaja injusta en el mercado político". En la segunda, el Tribunal confirmó la constitucionalidad de una norma del Estado de Michigan que prohibía que las "corporations" dispusieran del fondo social general para contribuciones o gastos dirigidos a apoyar o a oponerse a los candidatos a puestos estatales electivos. Bien es cierto que, al mismo tiempo, la propia norma autorizaba ese tipo de desembolsos siempre que fueran con cargo a recursos segregados con esa finalidad - "separate segregated funds», a los cuales podían contribuir las personas que quisieran. Aunque el Supremo admitió que la regulación estatal implicaba un cierto gravamen sobre los derechos de las "corporations" contemplados en la Primera Enmienda, justificó la diferencia de tratamiento res-

27. Arthur S. Miller, "On Politics, Democracy, and the First Amendment: a Commentary of First National Bank v. Bellotti, Washington and Lee Law Review, vol. XXXVIII, 1981, pp. 23-24.

28. 479 U.S. 238 (1986).

29. 494 U.S. 652 (1990). 
pecto del caso Buckley $v$. Valeo en que el interés del Estado en controlar "los efectos corrosivos y distorsionadores de agregados de riqueza inmensos (acumulados con la ayuda de su forma corporativa, que guardan escasa o nula relación con el apoyo público de las ideas políticas de la "corporation"), "estaba íntimamente relacionado con el propósito de impedir la corrupción y, además, la norma se ajustaba a tal fin".

El Tribunal Supremo, en suma, ha marcado una serie de pautas, ya recogidas por la doctrina ${ }^{30}$, que cabría reducir a las siguientes:

- El principio general es el de no intervención de los poderes públicos, si bien son admisibles la financiación pública de la elección presidencial bajo ciertas condiciones y la obligación de informar sobre los fondos recibidos y los gastos efectuados por los candidatos.

- Las medidas del legislador que pretenden impedir la aparición, o combatir la realidad, de la corrupción electoral son constitucionales. En cambio, aquellas dirigidas a suprimir o disminuir la influencia de determinados grupos de interés o de las personas más ricas, son inconstitucionales.

- Cuando se trata de modalidades de ejercicio de la democracia directa -iniciativa legislativa y referéndum-, previstas en las constituciones de más de una veintena de Estados, pero no en la Constitución federal, se consideran inconstitucionales cualesquiera límites a los gastos y contribuciones.

\section{LOS EFECTOS DE LA REGULACIÓN DE LA FINANCIACIÓN Y DE LA INTERPRETACIÓN DE LA MISMA POR EL TRIBUNAL SUPREMO}

La entrada en vigor de la Ley reguladora de las campañas electorales federales y de sus modificaciones y la jurisprudencia elaborada por el Tribunal Supremo desde 1974 hasta la fecha, no han servido apenas para mejorar la deteriorada imagen de unas elecciones en las que resulta primordial la recaudación de fondos para afrontar los gastos millonarios de las campañas, y cuya consecuencia notoria es la extraordinaria influencia política de los más ricos, sean éstos personas individuales o jurídicas. Antes al contrario, las medidas del legislador y su interpretación por el más alto Tribunal han abierto el camino a un marco no deseado, en el que han adquirido protagonismo los denominados PACs «Political Action Committees $\rightsquigarrow$ que representan precisamente aquello que se quería reformar $o$, al menos, atenuar: el poder del dinero en la vida política norteamericana.

Los PAC's, o Comités de Acción Política, son organizaciones creadas para recoger las donaciones dinerarias de simpatizantes y seguidores de grupos de intereses o de determinadas posiciones políticas, y para emplearlas en representación de los mismos en las campañas electorales y en actividades conexas. $\mathrm{Al}$ parecer,

30. Véase, por todos, Daniel Hays LowensteIn, "Campaign Finance and the Constitution", Political Parties and Elections in the United States, An Encyclopedia, vol.I, New York, Garland Publishing Inc., 1991, pp. 121-128. 
su creación data de los años 1940 cuando, "para escapar a la prohibición legal de que los sindicatos utilizasen sus propios recursos con fines políticos, el "Congress of Industrial Organizations" fundó en 1943 el primer Comité de acción política, al que debería suceder en 1955, después de la fusión de las dos organizaciones sindicales, C.I.O. y A.F.L. ("American Federation of Labour"), el C.O.P.E., o Comité de Educación Política, del que puede decirse que ha servido de modelo a todos los demás»31.

Si hemos de creer a los especialistas, los años 1970, en particular a partir de 1974, vieron florecer un sinfín de esos Comités, debido principalmente a la entrada en vigor de la norma antes repetida, que restringía claramente las abultadas contribuciones de individuos concretos que servían, a veces, de conductos a los intereses latentes de potentes grupos de negocios. La aprobación de la FECA y la interpretación jurisprudencial de la misma produjeron, entre otros, los siguientes efectos $^{32}$ :

1. Una proliferación de los Comités de acción política, que han ido asumiendo la función de movilización política pre-electoral que, hasta los años 1960 , desempeñaban los partidos políticos. En catorce años se multiplicaron por siete y hoy sobrepasan la cifra de los 4.000. Inevitablemente, los candidatos a un cargo público electivo cuentan con ellos como fuente primera y principal de recursos y su condicionamiento y dependencia son notables. La sospecha generalizada de relaciones y conexiones indebidas mancilla la cosa pública, sobre todo porque la mayoría de los Comités son filiales de 'corporations', o están patrocinados por empresas, $\mathrm{u}$ otras asociaciones.

2. El aumento de los gastos denominados independientes por parte de los Comites de acción política. Gastos independientes son los que se hacen sin la cooperación de, o la consulta con, candidato alguno, ni con agente o comisionado autorizados del mismo, y sin acuerdo con, ni a petición o sugerencia de candidato alguno, ni de sus colaboradores autorizados. (U.S. Code, vol. 2, cap. 14, sec. 431, 17). "Dada la protección constitucional actual de los gastos independientes, cualquier reforma que limitara más las contribuciones directas de los Comités supondría, sin duda, un aumento de esta forma de gasto, ${ }^{33}$.

3. La importancia adquirida por la fortuna o la riqueza personal como requisito para presentarse como candidato al Congreso ha sido otra de las consecuencias de la FECA. Si cualquier ciudadano desea iniciar una carrera política necesita contar con un patrimonio lo bastante saneado para lanzar una campaña que le asegure ciertas probabilidades de éxito. Los Comités propenden a apoyar a los que están ostentando el cargo y no suelen comprometerse con quien no aporta más que su "curriculum", conocimientos y/o reputación.

31. Jean-Pierre LASSAle, La démocratie Américaine. Anatomie d'un Marché Politique, París, Armand Colin, 1991, p. 200.

32. Sigo aquí, sobre todo, la obra de David B. Magleby and Candice J. Nelson, The Money Chase. Congressional Campaign Reform, Washington D.C., The Brookins Institution, 1990, pp. 18,19 y 20.

33. Op. cit. de D. B. Magleby and C. J. Nelson, p. 19. 
4. El incremento del denominado "soft money" (dinero incontrolado), es decir, de las aportaciones realizadas a partidos políticos estatales y locales, que se utiliza para identificar posibles simpatizantes, registrar votantes y promocionar candidaturas, que no están limitadas por ley y que acaba repercutiendo en las elecciones federales.

\section{A MODO DE CONCLUSIÓN}

La reforma de la legislación reguladora de la financiación de las elecciones que satisfaga al pueblo norteamericano continuará siendo una tarea pendiente del Congreso estadounidense. Han transcurrido cien años desde que se hiciera pública la necesidad de acabar con los perniciosos efectos del binomio "money-politics", y de insuflar nueva savia en la vida pública, facilitando la reincorporación de más del 50\% de los ciudadanos a la arena política, que se han apartado, por razones obvias, del debate y la contienda participativos. Es difícil, aunque no inimaginable, pensar en cambios legislativos que vayan más allá de la limpieza superficial de prácticas de corrupción demasiado conspicuas, porque las "reformas niveladoras que persiguieran disminuir la influencia de los grupos especiales de intereses y de las clases ricas ${ }^{34}$, tropezarían con los obstáculos insuperables que inexorablemente tiene que afrontar toda transformación social estructural, máxime en un país como los Estados Unidos de Norteamérica. Allí, tenía que ser allí, donde tanto esfuerzo ha costado que la condición de elector y de elegible no siguiera vinculada a la condición de propietario, donde no se ha impedido que la propiedad privada continuara actuando a su manera, es decir, funcionando como el poder dominante en la esfera política de la vida humana.

34. En palabras de mi buen amigo el Prof. Rod Smolla, en su obra Free Speech in an Open Society, New York, Alfed Knopf, 1992, p. 221. 